\title{
Association of physical activity and sedentary behavior at school with cardiovascular risk factors in adolescents
}

\section{Associacão da atividade física e comportamento sedentário realizados na escola com fatores de risco cardiovascular em adolescentes}

\author{
Priscila Cristina dos Santos ${ }^{1}$ \\ (iD https://orcid.org/0000-0002-0166-1201 \\ Luiz Rodrigo Augustemak de Lima² \\ (iD) https://orcid.org/0000-0003-0280-0151 \\ Bruno Gonçalves Galdino da Costa ${ }^{1}$ \\ (i) https://orcid.org/0000-0002-5132-1512 \\ Cilene Rebolho Martins ${ }^{3}$ \\ (iD) https://orcid.org/0000-0001-8352-654X \\ Giseli Minatto ${ }^{1}$ \\ (iD) https://orcid.org/0000-0001-5803-4201 \\ Juliane Berria \\ (D) https://orcid.org/0000-0003-2255-9297 \\ Everson Araújo Nunes ${ }^{4}$ \\ (iD https://orcid.org/0000-0001-9994-5677 \\ Edio Luiz Petroski ${ }^{1}$ \\ (iD) https://orcid.org/0000-0001-8480-0846 \\ Kelly Samara da Silva ${ }^{1}$ \\ (D) https://orcid.org/0000-0002-7356-1680
}

Abstract - The association of moderate to vigorous physical activity and sedentary behavior performed in the school context with cardiovascular risk factors is unclear. Thus, the purpose of this study was to evaluate whether MVPA and SB during school time are associated with single and clustered cardiovascular risk factors in 10- to 16-year-old school students. This study used the baseline data from a non-randomized controlled clinical trial ("MEXA-SE") conducted on 6th to 9th-grade students from schools in Florianopolis, Brazil. Skinfolds, resting blood pressure, 20 -m shuttle-run test, fasting glucose, triglycerides, total cholesterol, high-density lipoprotein cholesterol, and white blood cell counts were obtained. MVPA and SB were objectively measured with accelerometers. A minimum of 180 minutes was considered valid school-time for analysis. Multiple linear regression adjusted for age, sex and habitual physical activity was used. School-time MVPA was positively associated with the peak $\mathrm{VO}_{2}(\beta=0.17$ ml.kg. $\left.\mathrm{min}^{-1}\right)$, and inversely associated with sum of four skinfolds $(\beta=-0.96 \mathrm{~mm})$, diastolic blood pressure $(\beta=-0.36 \mathrm{mmHg})$, systolic blood pressure $(\beta=-0.301 \mathrm{mmHg})$; triglycerides $\left(\beta=-1.49 \mathrm{mg} \cdot \mathrm{dL}^{-1}\right)$, and clustered cardiovascular risk factors $(\beta=-0.123)$. School-time SB was positively associated with clustered cardiovascular risk factors $(\beta=0.033)$. In conclusion, independently of habitual physical activity level, school-time MVPA and a lower time in SB were associated to single and clustered cardiovascular risk factors. Thus, the promotion of strategies aimed increase MVPA and reduce SB at school may prevent the onset and early accumulation of cardiovascular risk factors in adolescence.

Key words: Adolescent; Cardiovascular abnormalities; Exercise; Sedentary lifestyle.

Resumo - $A$ associacão da atividade física moderada a vigorosa (AFMV) e do comportamento sedentário (CS) realizados no contexto escolar com fatores de risco cardiovascular é inconclusiva. Assim, o objetivo do presente estudo foi avaliar se a AFMV e o CS realizados durante o período escolar estão associados a fatores de risco cardiovasculares em escolares de 10 a 16 anos. Utilizou-se os dados da linha de base de um estudo clínico controlado não randomizado ("MEXA-SE") realizado com alunos do $6^{\circ}$ ao $9^{\circ}$ ano de escolas de Florianópolis, Brasil. Dobras cutâneas, pressão arterial, teste de vaivém de 20 metros, glicemia de jejum, triglicerídeos, colesterol total, lipoproteina de alta densidade e contagem de glóbulos brancos foram mensurados. A AFMV e CS foram medidos objetivamente com acelerômetros. Foi preconizado um periodo minimo de 180 minutos de uso para considerar o tempo válido e realizou-se regressão linear múltipla ajustada para idade, sexo e atividade física habitual. A AFMV foi associada positivamente com VO pico $\left(\beta=0,17 \mathrm{ml} \cdot \mathrm{kg} \cdot \mathrm{min}^{-1}\right)$ e inversamente associada à soma das quatro dobras cutâneas $(\beta=-0,96 \mathrm{~mm})$, pressão arterial diastólica $(\beta=0,36 \mathrm{mmHg})$, pressão arterial sistólica $(\beta=-0,301 \mathrm{mmHg})$; triglicerídeos $\left(\beta=-1,49 \mathrm{mg} . \mathrm{dL}^{-1}\right)$ e fatores de risco cardiovasculares agrupados $(\beta=-0,123)$. Houve também associação positiva do $C S$ com fatores de risco cardiovascular agrupados $(\beta=0,033)$. Conclui-se que a AFMV e o CS foram associados a fatores de risco cardiovasculares. Assim, a promoção de estratégias que visem aumentar a AFMV e reduzir o SB no contexto escolar pode impedir o aparecimento e o acúmulo precoce de fatores de risco cardiovasculares na adolescência. Palavras-chave: Adolescente; Anormalidades cardiovasculares; Estilo de vida sedentário; Exercício.
1 Federal University of Santa Catarina. School of Sports. Physical Education Department. Florianopolis, SC. Brazil.

2 Federal University of Alagoas. Institute of Physical Education and Sport. Maceio, AL. Brazil.

3 Faculdade Metodista Centenário Bacharelado em Educação Física. Santa Maria, RS. Brasil.

4 Federal University of Santa Catarina. Biological Sciences Center. Department of Physiological Sciences. Florianópolis, SC. Brazil.

Received: March 24, 2020 Accepted: August 17, 2020

How to cite this article Santos PC, Lima LRA, Costa BGG, Martins CR, Minatto G, Berria J, Nunes EA, Petroski EL, Silva KS. Association of physical activity and sedentary behavior at school with cardiovascular risk factors in adolescents. Rev Bras Cineantropom Desempenho Hum 2020, 22:e72397. DOl: http://dx.doi.org/10.1590/19800037.2020v22e72397

Copyright: This work is licensed under a Creative Commons Attribution 4.0 International License. 


\section{INTRODUCTION}

Although the clinical endpoint of cardiovascular disease mostly occurs during adulthood ${ }^{1}$, the presence of cardiovascular risk factors can already be observed during childhood and adolescence ${ }^{1}$. Several of the reasons behind the premature increase in cardiovascular risk seem to be related to the increase in physical inactivity rates ${ }^{2}$ and increase of time spent in sedentary behavior $(\mathrm{SB})^{3}$.

Studies have shown association among daily physical inactivity (through subjective and objective measures) ${ }^{1,4}$ and traditional cardiovascular risk factors in adolescents such as high blood pressure, high levels of triglycerides and total cholesterol (TC), low levels of high-density lipoprotein cholesterol (HDL-c) ${ }^{4}$ and the impairment of glycemic homeostasis ${ }^{1}$. However, many of these studies do not take into account the environment where physical activity is performed ${ }^{1,4}$. Adolescents spend a large portion of the day in school and more than $50 \%$ of total daily moderate to vigorous physical activity (MVPA) is achieved during school time $e^{5,6}$.

Over the last two decades, studies has also shown that SB can be associated with cardiovascular risk in young, however most of the studies are performed by subjective measures of SB, mainly on screen time devices ${ }^{7,8}$. A study with objective measures showed adolescents who are engage in more prolonged sedentary bouts per day had higher odds of increased clustered cardiometabolic risk score ${ }^{7}$. Conversely, according to a systematic review, null or inconsistent findings were observed for association of accelerometer derived SB with a clustered cardiometabolic risk score in longitudinal and cross-sectional studies ${ }^{8}$. Thus, it seems that the relation between SB and cardiometabolic risk is unclear in this population.

Considering the school period, the amount of sedentary time among adolescents is high ${ }^{9}$ and may be even greater than the period after school ${ }^{10}$. According to a study that evaluated Belgian adolescents (10-12 years), it was observed that during school time they spent 284.1 minutes in SB, while after school the adolescents spent 71.5 minutes in $\mathrm{SB}^{10}$. The school offers many opportunities for adolescents to be active (e.g. physical education classes and recesses) and is a place where policies focusing on adolescent health have been implemented ${ }^{11}$. Thus, there is a need to better understand the relationship between physical activity and SB performed in school with protection of cardiovascular risk factors. Therefore, the aim of this study was to evaluate whether accelerometer-measured MVPA and SB during school time are associated with single and clustered cardiovascular risk factors in elementary school students (from 10- to 16-year-old).

\section{METHODS}

\section{Participants}

This study analyzed the baseline data from the "MEXA-SE-De mãos dadas pela saúde" school intervention, a non-randomized, school-based controlled 
trial conducted in two schools in Florianopolis, Southern Brazil, between March and April 2015. The schools were selected by the Board of Education of the municipality and the inclusion and exclusion criteria were having students from 6th to 9th grades (26 schools), having more than 295 students enrolled (it was determined by the sample size) and having a covered sports gymnasium (5 schools). Once the criteria were met, the two largest schools were invited to participate, and as the participation of one of them was not authorized by its principal, a third school was invited (2 schools). Students who were unable to participate in the tests were excluded (i.e. students with disabilities or health issues that compromised their physical performance). The schools operate in two $4-\mathrm{h}$ shifts (8:00 am-12:00 pm and 1:00 pm-5:00 pm). Adolescents attend one of those two shifts, having classes either in the morning or afternoon. During a week, there are three classes of physical education with 45 minutes each, guided by a teacher.

A total of 1,011 students were invited to participate, and the parents or legal guardians of 567 students agreed to the study protocol by signing a consent form (56\% of eligible adolescents). The project was approved by the Ethics Committee of the Carmela Dutra Hospital (Protocol number 780.303) and it is also registered as a Clinical Trial (NCT02719704). All parents/ legal guardians informed consent before students' participation.

\section{Physical activity and Sedentary Behavior (independent variables)}

School-time MVPA and SB were measured with Actigraph ${ }^{\circledR}$ GT3x+ accelerometers, attached to the right hip with an elastic band. Students attended school in the morning or afternoon period ( $8 \mathrm{am}-12 \mathrm{pm}$ or $1 \mathrm{pm}-5$ $\mathrm{pm})$. The monitors were handed out daily at the beginning of the class and returned at the end of the class, over a period of one week. Students who had valid accelerometer data for at least 3 days (minimum of 180 minutes/ day - approximately $75 \%$ of total school time) were included in the analysis. Sedentary behavior and MVPA were classified using the following cut-offs: $<100$ and $>2,295$ counts per minute, respectively ${ }^{12}$.

\section{Single and Clustered Cardiovascular Risk Factors (dependent variables)}

For the blood collections that were performed in the present study, a total of 261 students participated. Blood samples $(15 \mathrm{~mL})$ were collected at the Public Primary Health Units near each school by trained nurses. The samples were collected after a 10 - $\mathrm{h}$ fast, processed, and stored in a biofreezer at $-80{ }^{\circ} \mathrm{C}$. Glucose, triglycerides, TC, and HDL-c were measured using a manual pipetting by a trained researcher, with semi-automatic and calibrated micropipettes into 96-well plates from previously stored aliquots. The ratio of TC to HDL-c was calculated. White blood cell counts were assessed in an automated hematology analyzer (ADVIA ${ }^{\circledR} 60$ Hematology System, Bayer Health Care).

The participants performed a $20-\mathrm{m}$ shuttle run test validated for the Brazilian population ${ }^{13}$ and maximum oxygen uptake (peak $\mathrm{VO}_{2}$ ) was esti- 
mated using a previously reported equation ${ }^{14}$. Biceps, triceps, subscapular and suprailiac skinfolds were measured with a Cescorf ${ }^{\circledR}$ adipometer by researchers trained by the International Society for the Advancement of Kinanthropometry (level 1) ${ }^{15}$. The sum of the four skinfolds was used for data analysis. In addition, the systolic and diastolic blood pressure of the participants was measured three times with an Omron ${ }^{\circledR}$ device (model HEM 742), with 3-min intervals between measurements and the mean value was considered for analyses.

$\mathrm{Z}$-scores were calculated separately for the sum of four skinfolds, systolic blood pressure, diastolic blood pressure, the inverse of maximum oxygen uptake, glucose, white blood cell count, and TC/HDL-c ratio considering age (10-12 years and 13-16 years) and sex (boys and girls). A clustered cardiovascular risk factor was calculated as the sum of the $\mathrm{z}$-scores of the cardiovascular risk factors ${ }^{16}$.

\section{Covariates}

Sex, age and habitual MVPA ( $<20$ and $\geq 420$ minutes per week) were measured with a validated questionnaire for Brazilian adolescents ${ }^{17}$.

\section{Statistical analysis}

Mean and standard deviation were calculated for the description of the data. Asymmetry, kurtosis, histograms and the Kolmogorov-Smirnov test were used to establish normality. The comparison between sex for the variables in the present study were identified by unpaired t-test and Mann-Whitney test. The associations of cardiovascular risk factors with school-time SB and MVPA were tested with linear regression analysis adjusted by sex, age and habitual MVPA (the normality of residuals was tested). Statistical significance was set at $\mathrm{p} \leq 0.05$. The analyses were performed using the STATA 15.0 for Windows software (Stata Corp, College Station, TX, USA).

\section{RESULTS}

Of the 567 students, 344 had valid accelerometer data (54.6\% girls, $12.36 \pm$ 1.3 years). Of these, not all provided complete datasets of the cardiovascular risk factors variables for be included in the analyses. Thus, for the present study 339 participants had valid blood pressure data, 336 had valid anthropometric data, 324 had valid peak $\mathrm{VO}_{2}$ data and 158 had valid blood draw (TC/HDL ratio showed the most missing data: 40.6\%). Table 1 shows the cardiovascular risk factors and minutes per day spent in MVPA and SB during school time according to sex. There was difference between sex for almost all study variables, except for systolic blood pressure ( $\mathrm{p}=0.722)$, glucose $(\mathrm{p}=0.442)$ and TC / HDL ratio $(\mathrm{p}=0.969)$. For each additional minute spent in school-time MVPA there was increase of $0.166 \mathrm{ml} . \mathrm{kg} \cdot \mathrm{min}^{-1}$ in peak $\mathrm{VO}_{2}$ $(95 \% \mathrm{CI}: 0.08 ; 0.25)$ and a reduction of $-0.96 \mathrm{~mm}$ in the sum of four skinfolds (95\%CI: -1.42 ; -0.49$)$, of $-0.362 \mathrm{mmHg}$ in diastolic blood pressure $(95 \% \mathrm{CI}$ : 
$-0.54 ;-0.19)$, of $-0.301 \mathrm{mmHg}$ in systolic blood pressure (95\%CI: -0.53;0.07); of $-1.479 \mathrm{mg} . \mathrm{dL}^{-1}$ in triglycerides (95\%CI: -2.66 ; -0.32$)$ and -0.12 of clustered cardiovascular risk factor (95\%CI:-0.20;-.05), regardless of sex, age and habitual MVPA. Glucose, TC/HDL-c ratio and white blood cell count were not significantly associated with MVPA after adjustments (Table 2).

In the unadjusted analysis was observed association between higher school-time $\mathrm{SB}$ and reduction in the peak $\mathrm{VO}_{2}(\beta=-0.073 ; 95 \% \mathrm{CI}:-0.095$; $-0.050)$, and increase in sum of four skinfolds $(\beta=0.189 ; 95 \% \mathrm{CI}: 0.075$; 0.303), in diastolic $(\beta=0.083 ; 95 \% \mathrm{CI}: 0.042 ; 0.125)$ and systolic blood pressure $(\beta=0.951 ; 95 \% \mathrm{CI}: 0.040 ; 0.151)$, in triglycerides $(\beta=0.280$; 95\%CI: $0.029 ; 0.527)$ and in the clustered cardiovascular risk factors score $(\beta=0.349 ; 95 \% \mathrm{CI}: 0.14 ; 0.56)$. However, when adjusted for sex, age and habitual MVPA, only the clustered cardiovascular risk factors score remained associated ( $\beta=0.033 ; 95 \% \mathrm{CI}: 0.011 ; 0.05)$.

Table 1. Distributions of components of cardiovascular risk factors, school-time moderate to vigorous physical activity, and school-time sedentary behavior in adolescents between 10 and 16 years old. Florianopolis, Santa Catarina, Brazil, 2015.

\begin{tabular}{|c|c|c|c|c|c|c|c|}
\hline \multirow{2}{*}{ Variables } & \multicolumn{2}{|r|}{ Total } & \multicolumn{2}{|r|}{ Boys } & \multicolumn{2}{|r|}{ Girls } & \multirow[t]{2}{*}{$p$-value } \\
\hline & $n$ & $($ Mean \pm SD) & $\mathrm{n}$ & $($ Mean \pm SD) & $\mathrm{n}$ & $($ Mean \pm SD) & \\
\hline Peak VO $\left(\mathrm{ml}_{2} \cdot \mathrm{kg} \cdot \mathrm{min}^{-1}\right)$ & 324 & $40.89 \pm 4.69$ & 148 & $42.82 \pm 4.91$ & 176 & $39.27 \pm 3.81$ & $<0.001^{\star}$ \\
\hline Sum of four skinfold (mm) & 336 & $46.84 \pm 23.86$ & 153 & $41.00 \pm 23.45$ & 183 & $51.72 \pm 23.15$ & $<0.001^{*}$ \\
\hline Diastolic blood pressure $(\mathrm{mmHg})$ & 339 & $64.30 \pm 8.82$ & 154 & $62.73 \pm 8.54$ & 185 & $65.6 \pm 8.87$ & $0.027^{\star}$ \\
\hline Systolic blood pressure $(\mathrm{mmHg})$ & 339 & $109.97 \pm 11.75$ & 154 & $109.27 \pm 12.53$ & 185 & $110.56 \pm 11.07$ & 0.722 \\
\hline Glucose $\left(\mathrm{mg} \mathrm{dL}^{-1}\right)$ & 157 & $78.04 \pm 16.99$ & 70 & $78.38 \pm 17.26$ & 87 & $77.81 \pm 16.87$ & 0.442 \\
\hline Triglycerides $\left(\mathrm{mg} \mathrm{dL}^{-1}\right)$ & 157 & $76.54 \pm 35.54$ & 70 & $69.52 \pm 29.33$ & 87 & $82.19 \pm 39.10$ & $0.004^{*}$ \\
\hline TC/HDL ratio & 155 & $3.50 \pm 1.35$ & 70 & $3.64 \pm 1.45$ & 87 & $3.39 \pm 1.25$ & 0.969 \\
\hline White Blood Cell (cells. $\mathrm{mm}^{-3}$ ) & 158 & $5.80 \pm 2.08$ & 71 & $5.44 \pm 1.42$ & 87 & $6.10 \pm 2.46$ & $0.004^{*}$ \\
\hline Self-reported physical activity (min.day) & 341 & $86.95 \pm 126.73$ & 156 & $102.87 \pm 143.34$ & 185 & $77.53 \pm 109.42$ & $0.010^{*}$ \\
\hline School-time MVPA (min.day ${ }^{-1}$ ) & 344 & $10.49 \pm 6.43$ & 156 & $14.33 \pm 6.74$ & 188 & $7.31 \pm 3.97$ & $<0.001^{*}$ \\
\hline School-time SB (min.day ${ }^{-1}$ ) & 344 & $139.28 \pm 22.25$ & 156 & $129.33 \pm 20.24$ & 188 & $147.54 \pm 20.42$ & $<0.001^{*}$ \\
\hline
\end{tabular}

Note. HDL: high-density lipoprotein cholesterol; TC: total cholesterol; MVPA: Moderate to vigorous activity in the school period; SB: sedentary behavior. ${ }^{*}$ Significant difference between sex (t-test and Mann-Whitney test). TC/HDL ratio had the most missing data: $40.6 \%$.

Table 2. Association between school-time moderate to vigorous physical activity and cardiovascular risk factors in adolescents between 10 and 16 years old. Florianopolis, Santa Catarina, Brazil, 2015.

\begin{tabular}{lccccccc}
\hline & \multicolumn{3}{c}{$\begin{array}{c}\text { School-time MVPA (min.day-1) } \\
\text { Unadjusted }\end{array}$} & \multicolumn{3}{c}{$\begin{array}{c}\text { School-time MVPA (min.day-1 } \\
\text { Adjusted }\end{array}$} \\
\cline { 2 - 8 } Variables & $\mathrm{n}$ & $\beta$ & $\mathrm{Cl} 95 \%$ & $\mathrm{p}$-value & $\beta$ & $\mathrm{Cl} 95 \%$ & $\mathrm{p}$-value \\
\hline Peak V0 & 324 & 0.306 & $0.23 ; 0.38$ & $\leq 0.001^{*}$ & 0.166 & $0.08 ; 0.25$ & $\leq 0.001^{*}$ \\
Sum of four skinfolds & 336 & -1.109 & $-1.49 ;-0.73$ & $\leq 0.001^{*}$ & -0.96 & $-1.42 ;-0.49$ & $\leq 0.001^{*}$ \\
Diastolic blood pressure & 339 & -0.387 & $-0.53 ;-0.24$ & $\leq 0.001^{*}$ & -0.362 & $-0.54 ;-0.19$ & $\leq 0.001^{*}$ \\
Systolic blood pressure & 339 & -0.367 & $-0.56 ;-0.17$ & $\leq 0.001^{*}$ & -0.301 & $-0.53 ;-0.07$ & $0.010^{*}$ \\
Glucose & 157 & $-0.370 ;$ & $-0.83 ; 0.09$ & 0.113 & -0.320 & $-0.88 ; 0.24$ & 0.259 \\
Triglycerides & 157 & -1.510 & $-2.45 ;-0.57$ & $0.002^{*}$ & -1.490 & $-2.66 ;-0.32$ & $0.013^{*}$ \\
TC/HDL-c ratio & 155 & -0.004 & $-0.04 ; 0.33$ & 0.827 & -0.035 & $-0.08 ; 0.01$ & 0.126 \\
White blood cells & 158 & -0.053 & $-0.11 ; 0.003$ & 0.063 & -0.24 & $-0.09 ; 0.04$ & 0.487 \\
Clustered cardiovascular risk factor & 148 & -0.126 & $-0.20 ;-0.05$ & $\leq 0.001^{*}$ & -0.123 & $-0.20 ;-0.05$ & $0.002^{*}$ \\
\hline
\end{tabular}

Note. HDL: high-density lipoprotein cholesterol; TC: total cholesterol. MVPA: Moderate to vigorous activity in the school period; *: represent significant associations $(\mathrm{p} \leq 0.05)$, statistical analysis was adjusted for sex, age and habitual physical activity. 
Table 3. Association between school-time sedentary behavior and cardiovascular risk factors in adolescents between 10 and 16 years old. Florianopolis, Santa Catarina, Brazil, 2015.

\begin{tabular}{|c|c|c|c|c|c|c|c|}
\hline \multirow[t]{2}{*}{ Variables } & \multicolumn{4}{|c|}{$\begin{array}{c}\text { School-time SB (min.day-1) } \\
\text { Unadjusted }\end{array}$} & \multicolumn{3}{|c|}{$\begin{array}{c}\text { School-time SB (min.day }{ }^{-1} \text { ) } \\
\text { Adjusted }\end{array}$} \\
\hline & $n$ & $\beta$ & $\mathrm{Cl} 95 \%$ & $\mathrm{p}$-value & $\beta$ & $\mathrm{Cl} 95 \%$ & $p$-value \\
\hline Peak VO & 324 & -0.073 & $-0.095 ;-0.050$ & $\leq 0.001^{*}$ & -0.024 & $-0.05 ;-0.00^{-4}$ & 0.050 \\
\hline Sum of four skinfolds & 336 & 0.189 & $0.075 ; 0.303$ & $\leq 0.001^{*}$ & 0.115 & $-0.02 ; 0.25$ & 0.086 \\
\hline Diastolic blood pressure & 339 & 0.083 & $0.042 ; 0.125$ & $\leq 0.001^{*}$ & -0.646 & $-0.02 ; 0.11$ & 0.090 \\
\hline Systolic blood pressure & 339 & 0.951 & $0.040 ; 0.151$ & $\leq 0.001^{*}$ & -0.464 & $-0.02 ; 0.11$ & 0.148 \\
\hline Glucose & 157 & 0.082 & $-0.038 ; 0.202$ & 0.181 & 0.015 & $-0.14 ; 0.17$ & 0.846 \\
\hline Triglycerides & 157 & 0.280 & $0.029 ; 0.527$ & 0.029 & 0.258 & $-0.62 ; 0.58$ & 0.113 \\
\hline $\mathrm{TC} / \mathrm{HDL}-\mathrm{c}$ ratio & 155 & -0.005 & $-0.014 ; 0.005$ & 0.320 & 0.001 & $-0.01 ; 0.01$ & 0.859 \\
\hline White blood cells & 158 & 0.153 & $0.001 ; 0.030$ & $0.041^{*}$ & 0.010 & $-0.01 ; 0.03$ & 0.304 \\
\hline Clustered cardiovascular risk factor & 148 & 0.349 & $0.14 ; 0.56$ & $\leq 0.001^{*}$ & 0.033 & $0.011 ; 0.05$ & $0.003^{*}$ \\
\hline
\end{tabular}

Note. HDL: high-density lipoprotein cholesterol; TC: total cholesterol. SB: sedentary behavior; *: represent significant associations ( $p$ $\leq 0.05)$, statistical analysis was adjusted for sex, age and habitual physical activity

\section{DISCUSSION}

School-time MVPA and SB were associated with clustered cardiovascular risk factor. In addition, school-time MVPA was inversely associated with the sum of skinfolds, blood pressure, and triglycerides, and positively correlated with aerobic fitness. These findings are important for health promotion at school and indicate the need to develop school-based interventions and public policies. Since the activities performed in this context already have an important reflection on the overall health of adolescents, these actions can help to prevent the early onset of cardiovascular risk factors at an early stage of development.

The peak $\mathrm{VO}_{2}$ is the best single indicator of aerobic fitness and low values represent an additional cardiovascular risk factor ${ }^{16}$ that should be included in the definition of metabolic syndrome ${ }^{18}$. The mean school-time MVPA was 12 min.day ${ }^{-1}$ and the association with $\mathrm{VO}_{2}$ peak suggests that each additional minute spent in school-time MVPA increase 0.17 ml.kg. $\mathrm{min}^{-1}$ of peak $\mathrm{VO}_{2}$. Another study also found a moderate positive association of MVPA with aerobic fitness in adolescents ${ }^{19}$, thus, additional engagement of adolescents in MVPA at school may improve aerobic fitness $^{19}$. School-time MVPA also was inversely associated with the sum of skinfolds in this study and corroborates with previous findings. Physical activity, especially when performed at vigorous intensity, is related to decreased adipose tissue ${ }^{20}$. According to a recent systematic review, physical activity interventions are effective in reducing body mass index in children and adolescents, for example ${ }^{11}$. Thus, the results emphasize the importance of school strategies that promote the increase in MVPA in order to help reduce the adipose tissue of adolescents.

The association between MVPA and blood pressure in adolescents has been observed in studies that measured physical activity with accelerometer $^{8,16}$ and accord with our finding, school-time MVPA significantly 
contributes to healthier blood pressure. A study showed that weekly patterns maintaining a higher percentage of MVPA or higher average intensity are associated with lower blood pressure in children and adolescents. Nevertheless, according to Hatfield et al. ${ }^{21}$, accelerometer-derived total activity counts may be more strongly associated with blood pressure than MVPA, but the underlying biological factors of this relationship are difficult to explain given an incomplete understanding of the pathways linking habitual physical activity and blood pressure.

Corroborating literature data, we found an association between schooltime MVPA and triglycerides in adolescents ${ }^{19}$. A possible explanation for this relationship is that MVPA induces an increase in lipoprotein lipase activity in skeletal muscle and adipose tissue which, together with the decrease in hepatic triglyceride synthesis, may reduce the concentrations of triglycerides ${ }^{22}$. Thus, adolescents engaged in MVPA tend to have blood pressure levels and a triglyceride profile within the healthy range ${ }^{19}$. In this way, changes in school-time MVPA may contribute to improvements in these indicators.

Since there is no clear definition of metabolic syndrome in adolescents, several studies ${ }^{7,16}$ have used a combined and continuous cardiovascular risk score. The rationale for the combination of metabolic syndrome components is supported by the high degree of inter-correlation because the components are not independently distributed in the population but cluster in some individuals ${ }^{16}$. Single risk factors may include day-to-day variations which can influence the associations. However, a composite score may compensate for fluctuations and allows for a more robust association with physical activity due to its continuous nature and because it is less prone to errors and cutoffs ${ }^{16}$.

The association between more minutes spent in school-time MVPA and clustering of risk factors found in the present study corroborates with previous studies ${ }^{16,23}$. Skered et al. ${ }^{23}$, suggested that, in order to reduce clustering of cardiovascular risk factors, it is necessary to perform physical activity of at least moderate to vigorous intensity. It is difficult to compare our results with other studies because the composite score is often composed by different cardiovascular risk variables. Even in the absence of consensus on which components should be part of clustering of cardiovascular risk factors, the association of school-time MVPA with the cluster of risk factor is important for the prevention of future cardiovascular diseases, especially in individuals who aggregate cardiovascular risk factors simultaneously.

Regarding to SB, it was observed that the volume spent in SB at school was positively associated with clustered cardiovascular risk factor regardless of physical activity levels. Bailey et al. ${ }^{7}$ found associations of sedentary bouts and the mean duration of daily breaks with hypertriglyceridemia and clustered cardiovascular risk score in adolescents (10-14-year). In addition, a recent research on children and adolescents showed that replacing SB with MVPA positively impacted cardiovascular risk factors, such as waist circumference, systolic blood pressure, low-density lipoprotein cholesterol, 
insulin, triglycerides, and glucose $\mathrm{e}^{24}$. It is important to highlight that the mentioned studies investigated SB throughout the day.

However, the association between objectively measured SB with accelerometers and cardiovascular risk factors in adolescents is not conclusive $\mathrm{e}^{1,8}$. Barker et al. ${ }^{25}$, for example, in a study with 534 European adolescents between 12.5 and 17.5 years, investigated the association of cardiovascular risk outcomes (sum of skinfolds, blood pressure, lipids, insulin resistance and clustered cardiovascular risk) with SB and did not find any association. A cross-sectional study about daily activity patterns observed three distinct clusters among students from 7-13 years old (prolonged sitters, breakers and prolonger movers) and although those students who breaking up sitting and spent most time in sporadic physical activity across the day had a lower adiposity risk, there was no association these identified patters with cardiometabolic risk factors ${ }^{26}$. Additionally, a systematic review showed results in the same direction, with null and inconsistent association between SB and cardiovascular risk factors ${ }^{8}$. Apparently, more evidences indicate a relationship among screen devices and health indicators than objective measures, mainly TV viewing which is associated with increased intake of unhealthy foods and unfavorable measures of body composition ${ }^{8,24}$.

Taken together, the results suggest further exploration of the time spent at school. For instance, improving the school environment and increasing recreational time are actions that may provide healthier metabolic profiles. Studies have investigated interventions in school settings, such as an increase in the intensity or number of physical education classes ${ }^{27}$. Positive results have been observed in blood pressure, TC/HDL-c ratio, triglycerides, aerobic fitness, and clustered $\mathrm{z}$-score after an intervention consisting of 60 minutes per day of MVPA at school compared to the control group (only 45 min of physical education twice a week) ${ }^{28}$. Thus, increasing the quantity and quality of physical education classes also seems to be a good strategy and is part of the Global Action Plan on Physical Activity 2018-2030 of World Health Organization ${ }^{29}$.

The method of this study poses some limitations, particularly in relation to its cross-sectional design that impairs cause and effect analysis, sampling non-randomized, loss of participants for paired analysis of the accelerometer data and cardiovascular risk factors reduces the external validity, possible prediction errors of the $\mathrm{VO}_{2}$ peak estimation and lack of objectively measured general MVPA and SB. The strengths of this study include the use of objective measurement of MVPA and SB which is more accurate for measuring time spent on these behaviors than a questionnaire; and evaluation of different cardiovascular risk markers (hypertension, dyslipidemia, diabetes mellitus, chronic inflammation) analyzed isolated and combined. In addition, our research constitutes one of the few studies from a middle-income country and indicates the need for more studies in the literature with similar contexts ${ }^{30}$. The sample of the present study, for example, was comprised of students in part time schools (only 4 hours per day), a school pattern similar in other low and middle-income countries 
but different to high-income countries where school schedules are generally full time (8/9am until 3/4pm).

\section{CONCLUSION}

In conclusion, MVPA performed during school time was inversely associated with single and clustered cardiovascular risk factors. Adolescents who spent more time in MVPA during school hours had lower sums of four skinfolds, blood pressure levels, triglycerides and clustered cardiovascular risk, as well as higher peak $\mathrm{VO}_{2}$ values. Sedentary behavior was associated only with clustered cardiovascular risk factor. These findings suggest that both increased MVPA and reduced SB in the school setting may contribute to cardiovascular health of adolescents. Thus, future school-based interventions aimed at promoting cardiovascular health among adolescents or preventing the onset of cardiovascular risk later in life should focus on increasing MVPA and reducing SB.

\section{Acknowledgements}

We would like to thank the Municipal Education Department of Florianopolis for authorizing the performance of the study; to all members of the school community (managers, teachers, parents and students) of schools involved for the support during the program's implementation. We also thank the funding for this research that was provided by the Brazil National Council for Scientific and Technological Development (CNpQ474184/2013-7) and the scholarships provided by Brazilian Coordination for the Improvement of Higher Education Personnel (CAPES). The sponsors had no role in the design and conduct of the study; collection, management, analysis, and interpretation of the data; preparation, review, or approval of the manuscript; and decision to submit the manuscript for publication.

\section{COMPLIANCE WITH ETHICAL STANDARDS}

\section{Funding}

Funding for this research was provided by the Brazil National Council for Scientific and Technological Development (CNpQ-474184/2013-7) and by Brazilian Coordination for the Improvement of Higher Education Personnel (CAPES).

\section{Ethical aspect}

The project was approved by the Ethics Committee of the Carmela Dutra Hospital (Protocol number 780.303). The research was written in accordance with the standards set by the Declaration of Helsinki.

\section{Conflict of interest statement}

The authors have no conflict of interests to declare. 


\section{Author Contributions}

Conception and design of the experiment: LRAL, ELP, CRB, GM and JB. Realization of the experiments: LRAL, ELP, CRB, GM and JB. Data analysis: PCS, LRAL and BGGC. Contribution with reagents/research materials/analysis tools: PCS, LRAL, BGGC, EAN and KSS. Article Writing: PCS, LRAL and BGGC. All authors read and approved the final version of the manuscript.

\section{REFERENCES}

1. Tarp J, Brønd JC, Andersen LB, Møller NC, Froberg K, Grøntved A. Physical activity, sedentary behavior, and long-term cardiovascular risk in young people: A review and discussion of methodology in prospective studies. J Sport Health Sci 2016;5(2):145-50.

2. Hallal PC, Andersen LB, Bull FC, Guthold R, Haskell W, Ekelund U, et al. Global physical activity levels: Surveillance progress, pitfalls, and prospects. Lancet 2012;380(9838):247-57.

3. Cooper AR, Goodman A, Page AS, Sherar LB, Esliger DW, van Sluijs EMF, et al. Objectively measured physical activity and sedentary time in youth: The International children's accelerometry database (ICAD). Int J Behav Nutr Phys Act 2015;12(1):1-10.

4. Williams BD, Richardson MR, Johnson TM, Churilla JR. Associations of Metabolic Syndrome, Elevated C-Reactive Protein, and Physical Activity in U.S. Adolescents. J Adolesc Health 2017;61(6):1-7.

5. Brooke HL, Corder K, Atkin AJ, van Sluijs EMF. A Systematic Literature Review with Meta-Analyses of Within- and Between-Day Differences in Objectively Measured Physical Activity in School-Aged Children. Sport Med 2014;44(10):1427-38.

6. Bailey DP, Fairclough SJ, Savory LA, Denton SJ, Pang D, Deane CS, et al. Accelerometry-assessed sedentary behaviour and physical activity levels during the segmented school day in 10-14-year-old children: The HAPPY study. Eur J Pediatr 2012;171(12):1805-13.

7. Bailey DP, Charman SJ, Ploetz T, Savory LA, Kerr CJ. Associations between prolonged sedentary time and breaks in sedentary time with cardiometabolic risk in 10-14-year-old children: The HAPPY study. J Sports Sci 2017;35(22):2164-71.

8. Carson V, Hunter S, Kuzik N, Gray CE, Poitras VJ, Chaput J, et al. Systematic review of sedentary behaviour and health indicators in school-aged children and youth : an update. Appl Physiol Nutr Metab 2016;41(6 Suppl 3):S240-65.

9. da Costa BGG, da Silva KS, George AM, de Assis MAA. Sedentary behavior during school-time: Sociodemographic, weight status, physical education class, and school performance correlates in Brazilian schoolchildren. J Sci Med Sport 2017;20(1):70-4.

10. Verloigne M, Ridgers ND, Chinapaw M, Altenburg TM, Bere E, Lippevelde W Van, et al. Patterns of objectively measured sedentary time in 10- to 12-year-old Belgian children : an observational study within the ENERGY- project. BMC Pediatr 2017;17(1):147.

11. Brown T, Moore TH, Hooper L, Gao Y, Zayegh A, Ijaz S, et al. Interventions for Preventing Obesity in Children. Cochrane Database Syst Rev 2019;7(7):CD001871.

12. Evenson KR, Catellier DJ, Gill K, Ondrak KS, McMurray RG. Calibration of two objective measures of physical activity for children.J Sports Sci 2008;26(14):1557-65.

13. Duarte MFS, Duarte CR. Validade do teste aeróbico de corrida de vai-e-vem de 20 metros. Rev Bras Ciên Mov 2001;9(3):7-14.

14. Léger LA, Mercier D, Gadoury C, Lambert J. The multistage 20 metre shuttle run test for aerobic fitness. J Sports Sci 1988;6(2):93-101.

15. Stewart A, Marfell-Jones M, Olds T, Ridder I. International Standards for Anthropometric Assessment. ISAK manual. Lower Hutt: New Zeland; 2011. 
16. Andersen LB, Riddoch C, Kriemler S, Hills A. Physical activity and cardiovascular risk factors in children. Br J Sports Med 2011;45(11):871-6.

17. Farias Júnior JC de, Lopes A da S, Mota J, Santos MP, Ribeiro JC, Hallal PC. Validade e reprodutibilidade de um questionário para medida de atividade física em adolescentes: uma adaptação do Self-Administered Physical Activity Checklist. Rev Bras Epidemiol 2012;15(1):198-210.

18. Andersen LB, Lauersen JB, Brønd JC, Anderssen SA, Sardinha LB, SteeneJohannessen J, et al. A new approach to define and diagnose cardiometabolic disorder in children. J Diabetes Res 2015;2015:1-10.

19. Poitras VJ, Gray CE, Borghese MM, Carson V, Chaput J, Janssen I, et al. Systematic review of the relationships between objectively measured physical activity and health indicators in. Appl Physiol Nutr Metab. 2016;239:S197-239.

20. Riso EM, Kull M, Mooses K, Hannus A, Jürimäe J. Objectively measured physical activity levels and sedentary time in 7-9-year-old Estonian schoolchildren: Independent associations with body composition parameters. BMC Public Health 2016;16(1):1-10.

21. Hatfield DP, Chomitz VR, Chui K, Sacheck JM, Economos CD. Exploring New Relationships Between Physical Activity Volume and Intensity and Cardiometabolic Risk in U.S. Adolescents. J Phys Act Health 2015;12(9):1312-9.

22. Williams PT. Health effects resulting from exercise versus those from body fat loss. Med Sci Sports Exerc 2001;33:S611-21.

23. Skrede T, Stavnsbo M, Aadland E, Aadland KN, Anderssen SA, Resaland GK, et al. Moderate-to-vigorous physical activity, but not sedentary time, predicts changes in cardiometabolic risk factors in 10-y-old children: The Active Smarter Kids Study. Am J Clin Nutr 2017;105(6):1391-8.

24. Reilly JJ, Steene-Johannessen J, Kriemler S, Page AS, Hansen BH, Wedderkopp N, et al. Cross-Sectional Associations of Reallocating Time Between Sedentary and Active Behaviours on Cardiometabolic Risk Factors in Young People: An International Children's Accelerometry Database (ICAD) Analysis. Sport Med 2018;48(10):2401-12.

25. Barker AR, Gracia-Marco L, Ruiz JR, Castillo MJ, Aparicio-Ugarriza R, González-Gross M, et al. Physical activity, sedentary time, TV viewing, physical fitness and cardiovascular disease risk in adolescents: The HELENA study. Int J Cardiol 2018;254:303-9.

26. Verswijveren SJJM, Lamb KE, Leech R, Salmon J, Timperio A, Telford RM, et al. Activity Accumulation and Cardiometabolic Risk in Youth: A Latent Profile Approach. Med Sci Sports Exerc 2020;52(7):1502-1510.

27. Klakk H, Chinapaw M, Heidemann M, Andersen LB, Wedderkopp N. Effect of four additional physical education lessons on body composition in children aged $8-13$ years - a prospective study during two school years. BMC Pediatr 2013;13(1):170.

28. Resaland GK, Aadland E, Nilsen AKO, Bartholomew JB, Andersen LB, Anderssen SA. The effect of a two year school-based daily physical activity intervention on a clustered CVD risk factor score - The Sogndal school-intervention study. Scand J Med Sci Sports 2017;28(3):1027-1035.

29. WHO. Draft WHO global action plan on physical activity 2018 - 2030. Vol. 2011, Who. 2017. 1-36 p.

30. Caleyachetty R, Echouffo-Tcheugui JB, Tait CA, Schilsky S, Forrester T, Kengne AP. Prevalence of behavioural risk factors for cardiovascular disease in adolescents in low-income and middle-income countries: an individual participant data metaanalysis. lancet Diabetes Endocrinol 2015;3(7):535-44.

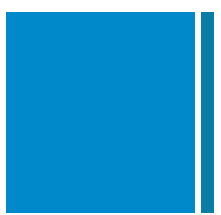

Corresponding author

Priscila Cristina dos Santos

Federal University of Santa Catarina.

Physical Education Department.

Address: Campus Universitario - Trindade. 88040-900, Florianopolis, SC, Brazil.

E-mail: prisantos.personal@gmail.com 